\title{
Experimental and numerical FEM-based determinations of forming limit diagrams of St14 mild steel based on Marciniak-Kuczynski model
}

\author{
M. Mianroodi ${ }^{*}$, G. Altmeyer ${ }^{2}$, S. Touchal ${ }^{1}$ \\ ${ }^{1}$ ICube laboratory, University of Strasbourg, CNRS, 4 Rue Boussingault, \\ 67000 Strasbourg, France \\ Phone: +33368852955 \\ *Email: mohammad.mianroodi@icube.unistra.fr \\ ${ }^{2}$ Laboratoire de Mécanique Gabriel Lamé, Université de Tours, Université d’Orléans, \\ INSA Centre Val de Loire, Polytech Tours, 7 avenue Marcel Dassault BP40, 37004 Tours, \\ France
}

\begin{abstract}
Forming Limit Diagrams (FLD) are used to design metal sheet processes and to choose appropriate material according to their formability. Development of simple and robust methods to determine the formability domain is then a major industrial issue. MarciniakKuczynski (M-K) plastic instability criterion is a classical and common approach used to predict numerical FLD. A convergence of the experimental conditions and theoretical M-K hypotheses is investigated. This analysis leads in the proposition of a simple experimental procedure based on classical instrumented biaxial testing machines to reproduce $\mathrm{M}-\mathrm{K}$ inplane loading conditions. Experimental results are compared with numerical simulations based on a finite element method implantation of $\mathrm{M}-\mathrm{K}$ model. This versatile implementation allows the coupling of the plastic instability criterion in ABAQUS with a large range of material behaviors. Application of these experimental and numerical procedures on commercial St14 mild steel leads to the relative differences between lower experimental points and numerical forming limits predictions that do not exceed $4 \%$ and $10 \%$ in the case of uniaxial and equibiaxial tension for initial prescribed defect ratio of 0.99 and 0.95 , and $22 \%$ in the case of plane tension. These procedures constitute ways easily implementable in the industry to obtain FLD at reduced costs that show good correlations between experimental results and numerical $\mathrm{M}-\mathrm{K}$ predictions.
\end{abstract}

Keywords: Forming limit diagram; Marciniak-Kuczynski; formability; finite element method; biaxial tensile tests.

\section{INTRODUCTION}

In industrial practice, formability of metal sheets is limited by critical phenomena such as diffuse necking and strain localization. To avoid scrapping of defective parts, it is important to understand how the forming process is performed and to get numerical tools to predict where the critical areas of necking and fracture are located. The forming process can then be 
analyzed and optimized before manufacturing tools, leading to time-saving, to the reduction of the costs and to a global improvement of the quality of products.

The origin of analysis of the forming limits was given in the 1940's. The first presentation, which includes a diagram similar to the typical Forming Limit Diagrams (FLD), was published by Gansamer in 1946 [1]. The concept of FLDs, as it is known today, was developed after different experimental tests and analytical investigations [2-6]. Marciniak and Kuczynski then developed a forming limit prediction model for strain localization, referred to $\mathrm{M}-\mathrm{K}$ in this study [7]. After deep experimental investigations on the relations between strain localization and geometrical and structural heterogeneities, M-K model is based on the supposed existence of initial geometrical imperfections in the sheet. Each sheet is represented with two regions: region $\mathrm{A}$ with uniform thickness and region $\mathrm{B}$ with geometrical imperfections. These imperfections may take the form of initial thickness heterogeneities or equivalent structural imperfections. During the forming process, the strain localization is supposed to occur in the imperfection zone. Some improvements have been proposed to this model in the expansion domain by taking into account the effects of the orientation of the band [8]. Strengths of this model are its ability to deal with a large class of materials including time-dependent materials and the possibility to implement it in Finite Element simulation software to simulate sheet metal forming processes [9-13]. This criterion is formulated with several hypotheses such as in plane loading and plane stress state, while the straining path of the safe zone may be chosen linear or not. On another hand, different experimental procedures have been developed to determine FLD. Among the most popular normalized methods, Nakazima and Marciniak tests are based on controlled stretching of a metal flank maintained on a die by a blankholder and submitted to the action of a moving punch [14-15]. Geometrical and mechanical observations of the specimen and of the loading conditions show out of plane stress and strain states, non-linear strain paths and strain gradients in the thickness of the sheet. Although these testing procedures are well representative of the complex straining conditions met during deep-drawing processes, one may observe the differences between the hypotheses used for the formulation of theoretical strain localization criteria and the conditions really encountered during experimental determination of FLD by classical tests based on punching of a sheet. Comparison of theoretical and experimental FLD results is then a sensitive question. To overcome these issues, a rapprochement between theoretical and experimental conditions is proposed in this paper by considering experimental determination of FLD from biaxial testing facilities. The aim of this paper is to bridge the differences between theoretical and experimental conditions used to determine FLD, to procure a new set of experimental data for St14 mild steel and to compare them with numerical predictions. After the presentation of the considered steel, FEM based M-K model formulation is developed. In the end, an experimental procedure including sheet heterogeneities obtained with modern experimental facilities based on multiaxial testing and on digital image correlation is presented.

\section{PRESENTATION AND MATERIAL MODELING OF ST14 MILD STEEL}

The material presented in this paper is a commercial low carbon St14 mild steel, composed of Iron, Carbon, Copper, Manganese, Phosphorous, Sulfur, Aluminum and Nitrogen. It is selected by industrial partners for its good machinery, deep drawing and stamping properties. 
This mild steel is easy to weld using any type of welding methods. The chemical composition is given in Table 1.

Table 1. Chemical composition (wt\%) of St14 mild steel [16].

\begin{tabular}{ccccccc}
\hline $\mathbf{C}$ & $\mathbf{S i}$ & $\mathbf{M n}$ & $\mathbf{P}$ & $\mathbf{S}$ & $\mathbf{A l}$ & $\mathbf{N}(\mathbf{p p m})$ \\
\hline 0.02 & 0.004 & 0.222 & 0.007 & 0.004 & 0.058 & 30 \\
\hline
\end{tabular}

A classical approach is followed to model elastoplastic behavior of St14 mild-steel. Details may be found in Lemaitre and Chaboche [17] and are briefly given in this section. A multiplicative decomposition of the transformation gradient $\mathrm{F}$ using a reversible elastic part and an irreversible plastic one leads to: $F=F_{e} \cdot F_{p}$, where $F_{e}$ and $F_{p}$ denote respectively the elastic and plastic parts of the transformation gradient. Differentiation of this transformation gradient leads then to the definition of the velocity gradient $\mathrm{L}: \mathrm{L}=\dot{\mathrm{F}} \cdot \mathrm{F}^{-1}$. Deep-drawing of metal sheets is generally characterized by small elastic deformations e observed before plastic deformations. Transformation tensor $\mathrm{F}$ can then be approximated with: $\mathrm{F}_{\mathrm{e}}=$ $(1+\mathrm{e}) . \mathrm{R}$, where $\mathrm{R}$ denotes the elastic rotation operator. Introducing this expression in the definition of the velocity gradient, one may obtain: $L=\dot{R} \cdot R^{-1}+e^{0}+R \cdot \dot{F}^{p} \cdot\left(F^{p}\right)^{-1} \cdot R^{-1}$, where $\mathrm{e}^{\circ}$ is an objective measure of the elastic strain rate. In the following simulations, Jaumann derivative will be used for convenience reasons as it is implemented in ABAQUS FEM software. The total strain rate is the symmetric part of the velocity gradient. Its additive decomposition into elastic and plastic parts leads to the following expression of the plastic strain rate: $\mathrm{D}^{\mathrm{p}}=\mathrm{D}-\mathrm{e}^{\circ}$. For FLD determination, it is common to apply the load in the principal directions of anisotropy, leading to a null elastic spin. A simplified formulation of the material laws, close to the small strain formulation, may then be used. When these loading conditions are not observed, equations may be written in a rotated frame leading to the same simplified expressions of the material behavior. Following a phenomenological approach based on thermodynamically irreversible processes detailed in Lemaitre and Chaboche [17], elasto-viscoplastic relations are developed to represent phenomena observed during cold forming of metal sheets, as for example the evolution of hardening or the sensibility to the loading rate. In this work, the evolution of the time-dependent hardening is obtained by using a classical power law:

$$
R=R_{0}+k \bar{\epsilon}^{\mathrm{n}} \dot{\bar{\epsilon}}^{\mathrm{m}}
$$

where $\mathrm{R}_{0}, \mathrm{~m}, \mathrm{n}$ and $\mathrm{k}$ are respectively the hardening constant, strain rate sensitivity exponent, strain hardening exponent and strength constant [18]. Identification of material parameters of this model for St14 mild steel has been carried out and the results are given in Table 2.

Table 2. Mechanical properties of St14 mild steel $[18,19]$.

\begin{tabular}{cccccccc}
\hline $\mathbf{E}$ & $\mathbf{v}$ & $\begin{array}{c}\boldsymbol{\rho} \\
(\mathbf{G P a})\end{array}$ & $\begin{array}{c}\boldsymbol{\sigma}_{\mathbf{e}} \\
\left(\mathbf{k g} / \mathbf{m}^{\mathbf{3}}\right)\end{array}$ & $\begin{array}{c}\boldsymbol{\sigma}_{\mathbf{m}} \\
(\mathbf{M P a})\end{array}$ & $\begin{array}{c}\mathbf{k} \\
(\mathbf{M P a})\end{array}$ & $\mathbf{n}$ & $\mathbf{m}$ \\
\hline 210 & 0.3 & 7860 & 145 & 500 & 660 & 0.19 & 0.012 \\
\hline
\end{tabular}


Further details about the finite transformation framework and plasticity modeling may be found in [20]. Different procedures have been developed to study the formability of such steel sheets. Some of them are purely experimental while others are based on analytical models or are based on purely numerical approaches. In the next sections, two procedures based on experimental and numerical approaches will be applied to the determination of FLD for St14 mild steel.

\section{MARCINIAK-KUCZYNSKI MODEL AND NUMERICAL SIMULATION}

Plastic instabilities are largely influenced by imperfections that may be present in structures. According to multi-zones models, localization is expected to produce in regions of the metal sheet affected by such common defects. Nature of these defects may, for example, be related to the composition of the alloy, to grain sizes and repartitions, to geometrical heterogeneities, to residual stresses or more generally to material imperfections [21]. In M-K approach, an equivalent geometrical defect is defined to reproduce the destabilizing effects of all present imperfections regardless of their real nature. A band of reduced thickness is then defined in $\mathrm{M}-\mathrm{K}$ model partitioning a local space of the metal sheet into two regions as shown in Figure 1: region $\mathrm{A}$ is a region with nominal thickness $t$ while the region $\mathrm{B}$ is affected by a thickness reduction $t^{B}$ in a band of width $w^{B}$.

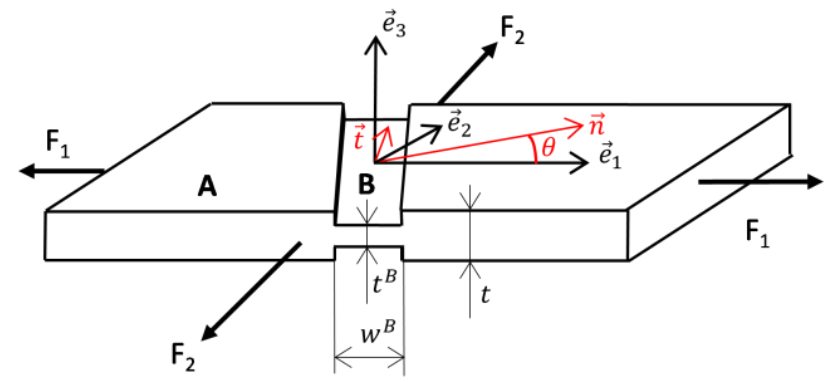

Figure 1. Definition of zones A and B in M-K model [22].

This user-defined defect is represented and introduced in the model by the initial thickness ratio $f_{0}$ defined by:

$$
f_{0}=\frac{t_{0}^{B}}{t_{0}}
$$

with $t_{0}$ and $t_{0}^{B}$ are the initial thicknesses of the sheet and inside the band. Common values of the initial thickness ratio $f_{0}$ are comprised between 0.95 and 0.999 [23]. When $f_{0}$ tends to 1 , the sheet tends to a geometrical initially homogeneous domain, leading to higher formability predictions. No localization can be predicted with this model for a homogeneous metal sheet. This imperfect sheet is then loaded following different loading paths to investigate its formability limits. In this paper, a constant and linear loading rate in forces space is chosen to be consistent with experimental conditions. Noting $F_{1}$ and $F_{2}$ the major and minor forces taken in the longitudinal (rolling) and tangential directions, the loading ratio $\alpha$ is defined by:

$$
\alpha=\frac{F_{2}}{F_{1}}
$$


The values of $\alpha$ are chosen between 0 and 1, respectively representing uniaxial tension and equibiaxial tension. In contraction domain, formability limits are shown to be influenced by the initial orientation of the imperfection band. For a given loading path, different orientations of the band have then to be envisaged and simulated to detect the most critical situation leading to the lower formability prediction. Current position of the band can be expressed as a function of the initial orientation of the band and the strain state [8,24]:

$$
\tan (\theta)=\exp \left(\epsilon_{1}-\epsilon_{2}\right) \tan \left(\theta_{0}\right)
$$

Strain and stress states are computed and stored for each loading step. Observation of relative evolutions of the mechanical fields inside and outside the imperfection band shows a superior increase of the strain rate in the band. This phenomenon leads to a concentration of the strain inside the band and then to the strain localization. Different localization indicators may then be constructed to predict localization. In this paper, the out-of-plane strain rate ratio is used as a strain localization measure. Localization is predicted when this ratio exceeds a userpredefined value [18]:

$$
S_{M K}=\frac{\epsilon_{33}^{B}}{\epsilon_{33}^{A}}
$$

It can be shown that the value of this threshold may be taken in a range of, for example, 5 to 10 and that its choice should not influence strain localization predictions as strain rate evolves exponentially in zone B near localization. Predictions are then not sensitive to this parameter, but high values of the threshold may lead to numerical instabilities. Different methods may be set up to implement the M-K model, from purely analytical developments to FEM simulation. In this paper, this second choice has been favored and ABAQUS software has been used for numerical applications. A $180 \mathrm{~mm}$ x $180 \mathrm{~mm}$ length and $1 \mathrm{~mm}$ thickness metal plate modeled on ABAQUS and loaded using a loading ratio $\alpha$ defined in the force space. The principle load is equal to 400MPa. A geometrical imperfection is introduced in this band using M-K approach is characterized by its initial thickness ratio and orientation. Different initial values of these parameters which are used for the simulations are represented in Table 3. One point in the corner of this plate is fixed by Encastre boundary condition and the displacement of the bottom side is blocked in the transversal direction and the right side is blocked in the longitudinal direction. Using these loading conditions, evolutions of strain and strain rate tensors are then stored for two representative elements respectively taken in zones A and B of a mesh with 21600 linear hexahedral mesh of type C3F8R elements mesh. The FLDs typical configurations are obtained for particular principal strains ratios as illustrated below in Figure 3 for $\alpha=0$ and an orientation band equal to $\theta=20^{\circ}$. 


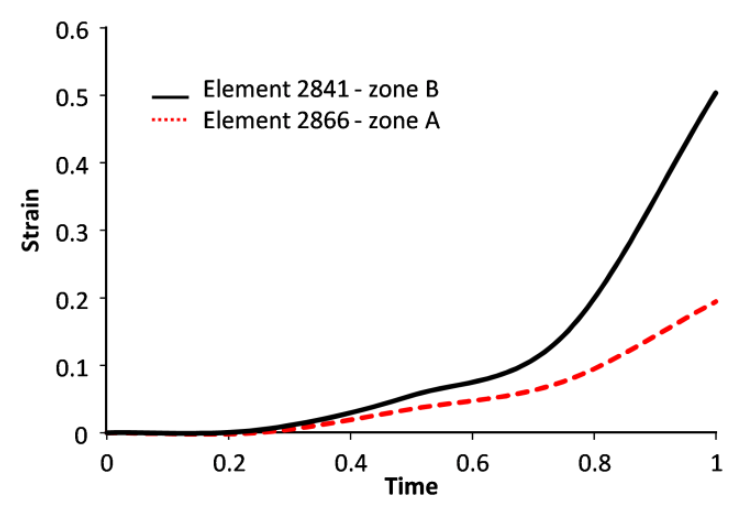

(a) $\theta=0^{\circ}$

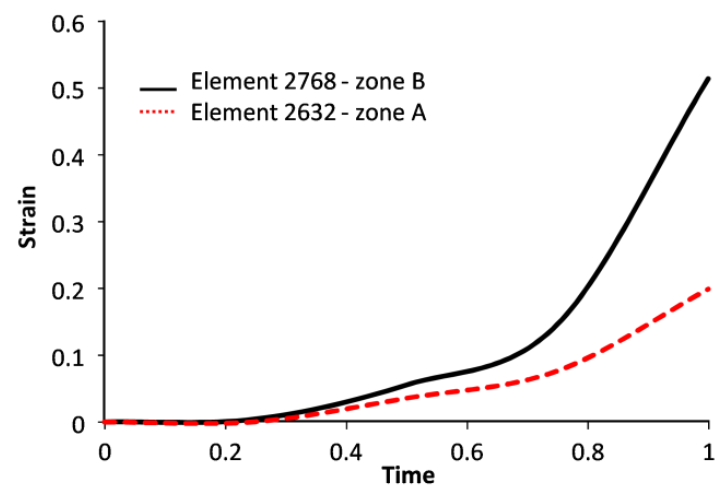

(b) $\theta=20^{\circ}$

Figure 2. Strain-Time curves for $\alpha=0.4, \theta=0^{\circ}$ (a) and $\theta=20^{\circ}(\mathrm{b})$.

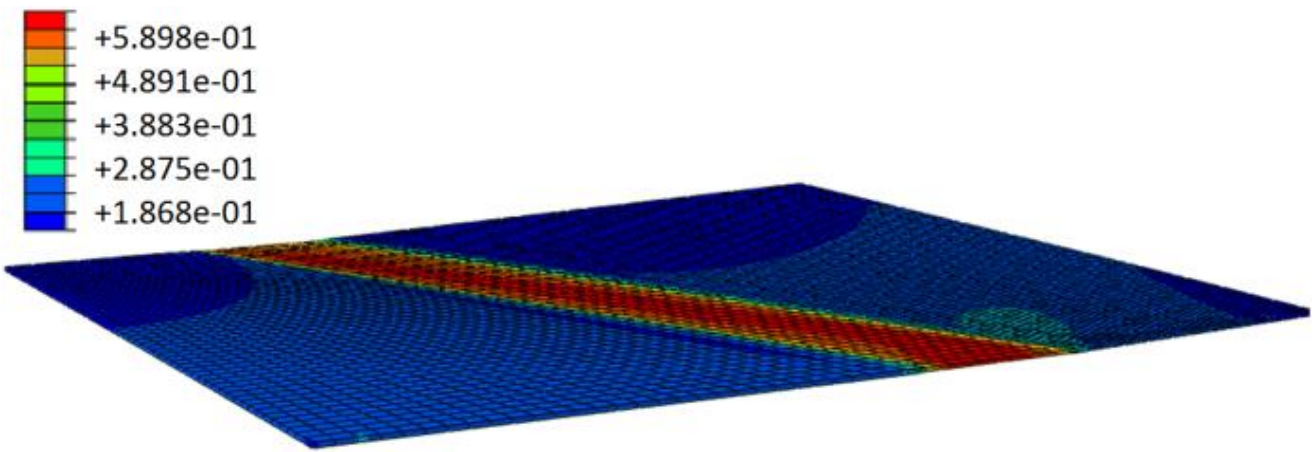

Figure 3. Max strain for $\alpha=0, \theta=20^{\circ}$.

The simulation continues until reaching the strain localization criterion. Critical strains values are stored at localization and reported in the FLD represented in Figure 4 for three different orientations band $0^{\circ} ; 20^{\circ}$ and $40^{\circ}$. Shapes of FEM based FLD and sensibility to the initial orientation of the band are consistent with classical results based on analytical developments. Formability predictions are for instance influenced by $\theta$ in contraction domain. Final numerical FLD is constructed by selecting the lower points for each loading path.

Table 3. Numerical properties of the imperfection zone B.

\begin{tabular}{cccc}
\hline $\mathbf{w}_{\mathbf{0}}^{\mathbf{B}}(\mathbf{m m}) \mathbf{t}_{\mathbf{0}}^{\mathbf{B}}(\mathbf{m m})$ & $\boldsymbol{f}_{\mathbf{0}}$ & $\boldsymbol{\theta}$ \\
\hline 10 & 0.90 & 0.90 & $0^{\circ}-40^{\circ}$ \\
10 & 0.95 & 0.95 & $0^{\circ}-40^{\circ}$ \\
10 & 0.99 & 0.99 & $0^{\circ}-40^{\circ}$ \\
\hline
\end{tabular}




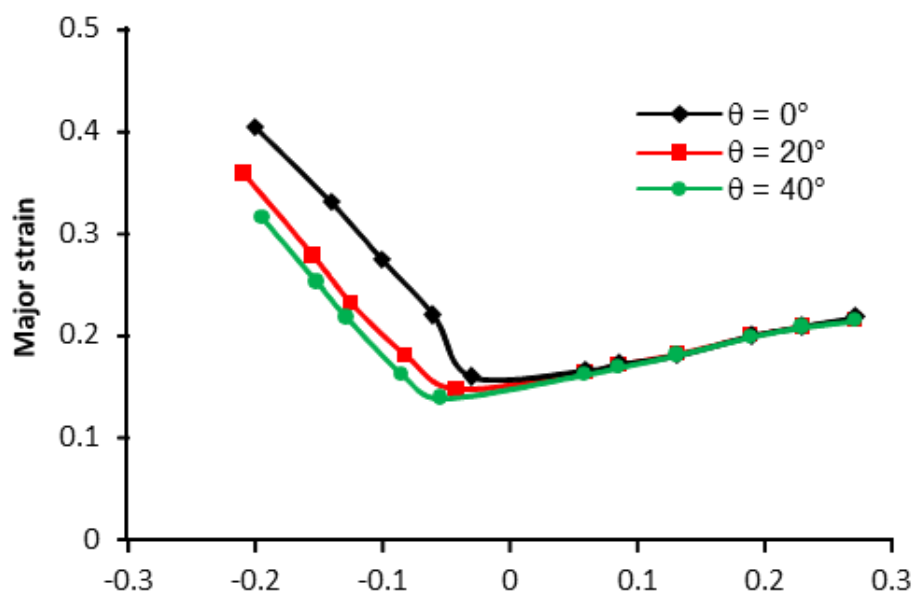

Figure 4. Numerical FLD obtained with a FEM based M-K model for different values of orientation band $\theta$.

\section{EXPERIMENTAL PROCEDURE FOR DETERMINATION OF FLD USING MULTI-AXIAL TENSILE TESTS}

Experimental studies constitute a direct and efficient way to determine FLD. Several testing procedures have been designed to study sheet metal forming. Among them, Nakazima [14] and Marciniak tests are probably the most popular and are defined by international standards such as ASTM E2218-02 and ISO 12004-2:2008 [25-27]. Following these tests, specimens with different geometries are placed in a stamping press or a testing device equipped respectively with hemispherical or cylindrical punches [28-30]. These tests require the presence of specifically developed testing machines, of stamping presses or of special devices developed to adapt existing tensile machines and the use of several geometries to reproduce the different strain ratio from uniaxial tensile test to equibiaxial conditions. During the test, out of plane loads are imposed to the specimen, generating strain gradients in the thickness direction that are not taken into account in the formulation of classical strain localization criteria. Other convenient experimental procedures in which the load is applied in the longitudinal and tangential directions of the sheet during all the test may be used to get closer experimental and theoretical loading conditions and strain and stress fields [31-32]. 

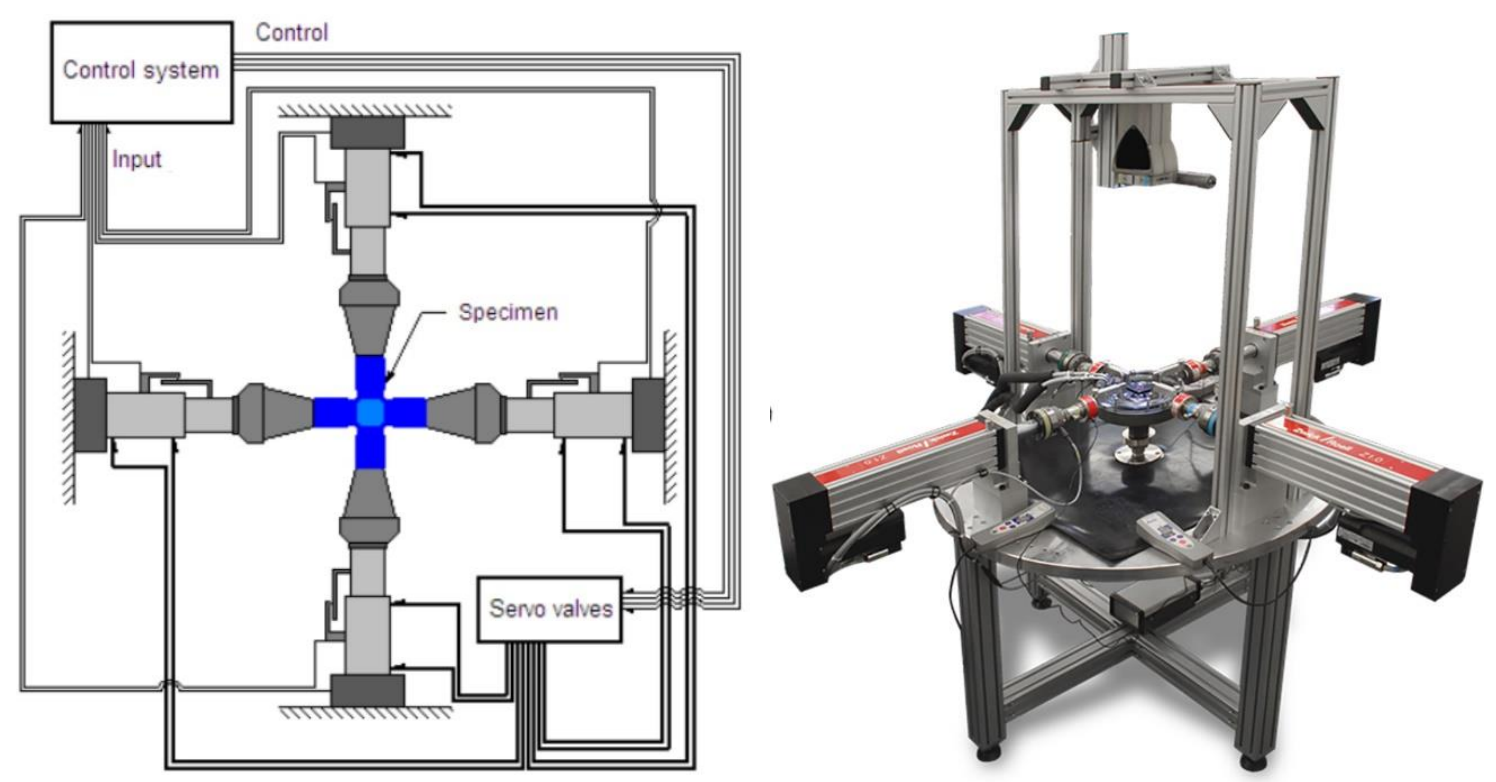

Figure 5. Schematic Zwick Biaxial tensile test machine [33-34].

Biaxial traction test is a simple way to investigate the materials behavior under loading and requires only the presence of biaxial testing machine, specific cross specimens, and digital image correlation chain to record the displacement field during the test [35]. A Zwick universal testing machine is used at CAN company to perform the different tests, imposing different stress or force ratios to reproduce the different loading paths of the FLD, as represented in Figure 5. For applying the load on flat plates or cruciform specimen in two different directions, this type of machine is required [36]. The type of load is applied in compression or tension-type. The load must be applied continuously, symmetrically and the center of the specimen must stay in the center of the testing machine during the test. This machine has four arms to apply forces. These forces are applied by hydraulic actuators. Typically, they used a servo and piston to control system. Schematic of the biaxial tensile machine is shown in Figure 5. One cross specimen $180 \mathrm{~mm} \times 180 \mathrm{~mm}$, cut in a $1 \mathrm{~mm}$ thick metal sheet by a Siemens $828 \mathrm{D}$ CNC machine, is used for every loading condition. The geometry of them is not specific to the loading path. Some imperfections are preexisting in the metal sheets due for example to crystallographic effects or to roughness after rolling operations. These imperfections may be seen as factors favoring the initiation of strain localization and then as factors equivalent to a preexisting defect. To explore the influence of M-K initial imperfection hypothesis, imperfection bands are cut in some specimens to reproduce the geometrical imperfection with a defect ratio $f_{0}$ of 0.95 .

At the beginning of the test, a $10 \mathrm{~N}$ preloaded is applied to each side of the specimen. Loads are then applied in both directions according to the force loading ratio $\alpha$. This ratio is made varying from 0 to 1 by increments of 0.1 to obtain the different points of the FLD. The test is continued until strain localization or failure. An example of a load is given in Figure 6. In this case, a force is applied after the preload step up to $400 \mathrm{~N}$ in the longitudinal direction of the sheet during $1.426 \mathrm{~s}$ corresponding to a loading ratio $\alpha$ of 0 . 


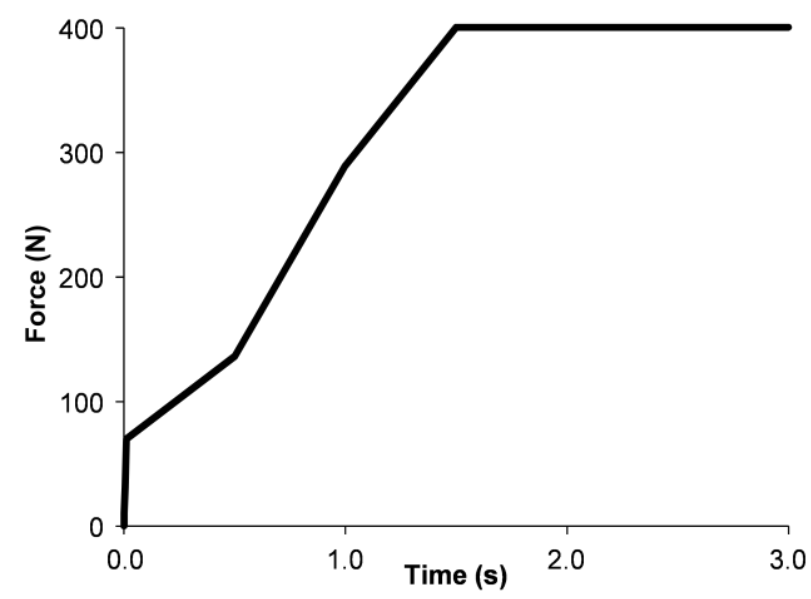

Figure 6. Force-Time curve for experimental test.

Full-field measurement techniques are based on the comparison of the digital image of the specimen before and after applying a load increment. Displacement and strain fields are then estimated using and Digital Image Correlation techniques [37-38]. This technic can be applied to FLD predictions [39-40]. In our study, 25 images of 6Mpx are recorded every second by an Aramis 3D camera with a timer and are then analyzed using GOM DIC software to determine the critical strains at localization. Experimental results of FLD obtained for St14 thin sheets and the influence of the introduction of an initial defect in the sheet will be discussed in the last section.

\section{COMPARISON OF EXPERIMENTAL AND NUMERICAL FLD PREDICTIONS FOR ST14 MILD STEEL}

When designing experimental procedure and numerical simulation, particular attention has been paid on the reproduction of similar in-plane loading and boundary conditions. With such close hypothesis, results of experimental and numerical approaches can now be compared on the commercial nuance of St14 mild steel presented in previous sections.

Numerical FEM-based M-K results are reported in Figure 7 for two initial defect ratio of 0.95 and 0.99 . With a ratio of 0.95 , the curve may be approximated by two lines by joining the predicted limit points at localization. These lines are respectively a decreasing one in the contraction domain and another one increasing in the expansion. The lower value is given by the intersection of these lines for plane tension (PT). Noticeable values of major strain at localization are respectively $0.44,0.18$ and 0.28 for uniaxial tension (UT), plane tension and equibiaxial expansion (EE). Another curve is obtained for a ratio of 0.99 . This curve is situated above the previous one and values of the major strains of $0.66,0.22$ and 0.36 are reported for UT, PT, and EE. On Figures 8 and 9, original experimental results are also plotted for a comparison with a ratio defect of 0.99 and 0.95 respectively. For a ratio of 0.99 , localization is predicted above a major strain of 0.52 for uniaxial traction load. For the rest of the domain, scatter in results is observable. An interesting line passing close to points with major strains from 0.45 near uniaxial tension to 0.4 near equibiaxial expansion is observable. 


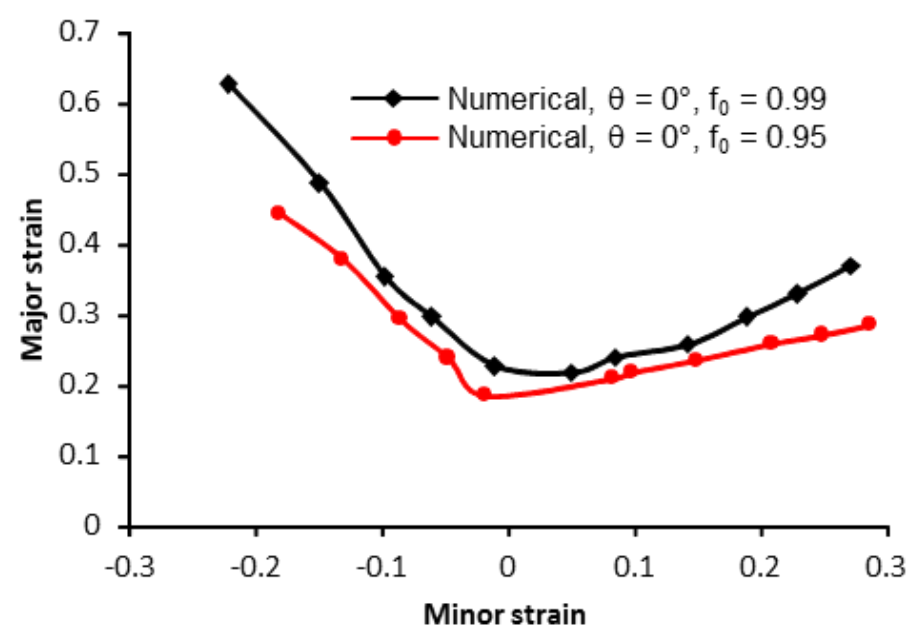

Figure 7. Numerical FLD results for $f_{0}=0.95$ and $f_{0}=0.99$.

This shape has for example been pointed out for fracture behavior of ductile materials in [4142]. Further developments could then be interesting to compare these points and results obtained with fracture criteria. Experimental localization points located from either side of this curve are observed. Within this set of results, scatter of experimental results for this set of parameters only allows the observation of general trends. It is shown by comparing numerical and experimental points for a ratio of 0.99 that experimental points are located above numerical predictions for around $75 \%$ of the experimental points, see Figure 8 . For the rest of the $25 \%$ of the lower experimental strain localization predictions, they are located just on the curve plotted from numerical M-K model. For UT case, relative error between experimental point and numerical prediction do not exceed 3.6\%. FLD 0 experimental point appears to tend toward fracture mode and will not be considered. For equibiaxial expansion case, the relative difference between numerical and experimental minor strain points is not greater than $2 \%$. It can be considered that numerical M-K predictions constitute then a lower bound to experimental results.

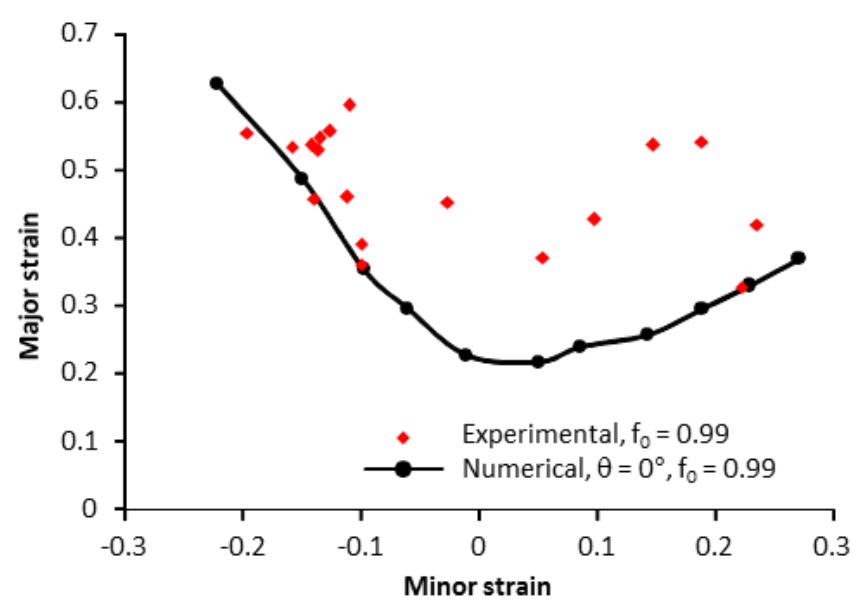

Figure 8. Experimental and numerical FLD results for $f_{0}=0.99$. 
For a ratio of 0.95 , the results are largely less dispersed (see Figure 9). Minimal values of the major strain at localization of $0.46,0.22$ and 0.28 are observed respectively for UT, PT, and EE loading ratios. These ratios are in good accordance with the previously discussed numerical results. In fact, experimental points might be classed in two groups. A first group could be constituted by points situated near two lines joining UT-PT and PT-EE experimental predictions. Another one is grouping upper points located near a line joining UT and EE predictions. Relative errors between experimental and numerical results are 10\%, 22\% and $8 \%$ respectively for UT, PT and EE. For a defect ratio of 0.95 , a good correlation between numerical and the first group of experimental results is still observable. Excluding one experimental point, numerical predictions constitute a lower bound to experimental results.

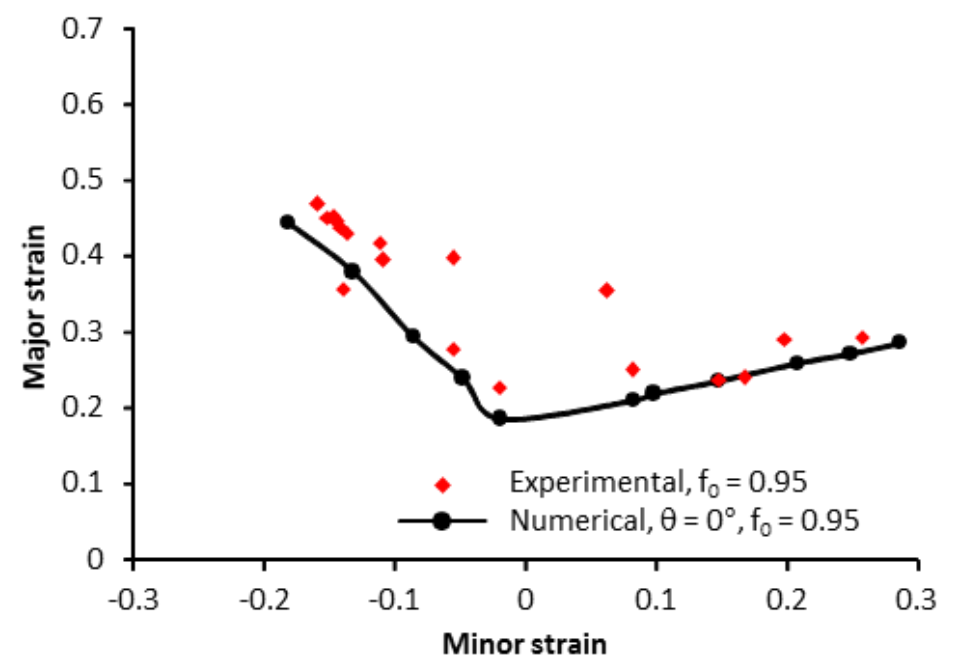

Figure 9. Experimental and numerical FLD results for $f_{0}=0.95$.

\section{CONCLUSIONS}

Two complementary approaches have been developed to study strain localization occurring in commercial St14 mild steel sheets during forming operations. These experimental and numerical approaches are designed to study the formability of metal sheets by reproducing the same planar loading and boundary conditions. The experimental procedure is based on conventional biaxial tensile testing machine instrumented with DIC devices for displacement field measurement. It allows the determination of FDL without requiring any development of specific FLD mounting or the use of specific FLD testing machine. Strain localization is studied on experimental specimens with initial defects introduced by a digital milling machine. The second approach relies on a numerical FEM implantation of MarciniakKuczynski model. In this procedure, strain localization is expected to appear in zone presenting an initial thickness defect. The fully 3D finite transformation framework is implemented in ABAQUS FEM software. This implementation is versatile and easily adaptable to a large class of materials including elasto-plastic or visco-plastic behaviors. This numerical procedure allows strain localization predictions using material parameters 
commonly available from datasheets without being sensitive to damage parameters identification strategies.

Experimental and numerical procedures are then applied and compared on St14 mild steel. A set of original experimental results is proposed in this paper. Both give close results for sheets presenting initial defect ration of 0.95 . Relative errors between experimental and numerical results are $10 \%, 22 \%$ and $8 \%$ respectively for uniaxial tension (UT), plane tension (PT) and equibiaxial expansion (EE). For an initial ratio of 0.99 , relative errors between experimental and numerical results are below $4 \%$ and $2 \%$ respectively for UT and EE, but experimental results do not seem being significant for PT. Application of these experimental and numerical procedures on commercial St14 mild steel leads then to limited relative differences between lower experimental points and numerical forming limits predictions. The numerical one is slightly more conservative and seems then suitable for estimating FLD with a safety coefficient. For smaller initial defects, further developments should be carried out to relate results with fracture criteria.

\section{REFERENCES}

[1] Gamsamer M. Strength and Ductility. Trans. ASM. 1946.

[2] Keeler SP, Backofen WA. Plastic instability and fracture in sheets stretched over rigid punches. Trans. ASM. 1963; 56:25-48.

[3] Keeler SP. Determination of forming limits in automotive stampings. Sheet Metal Industries. 1963; 42:683-91.

[4] Goodwin GM. Application of strain analysis to sheet metal forming problems in the Press Shop. SAE Technical Paper: 60:767-774; 1968.

[5] Altmeyer G, Abed-Meraim F, Balan T. Comparison of forming limit diagrams predicted with different localization criteria. Steel Research International. 2008; 79(1):24-31.

[6] Abed-Meraim F, Balan T, Altmeyer G. Investigation and comparative analysis of plastic instability criteria: Application to forming limit diagrams. The International Journal of Advanced Manufacturing Technology. 2014; 71(5-8):1247-1262.

[7] Marciniak Z, Kuczynski K. Limit strains in the process of stretch forming sheet metal. International Journal of Mechanical Sciences. 1967; 613-620.

[8] Hutchinson JW, Neale KW, Needleman A. Sheet Necking-I. Validity of plane stress assumption of the long-wave length approximation. Mechanics of Sheet Metal Forming. 1978; 116-126.

[9] Marciniak Z, Kuczynski K, Pokora T. Influence of the plastic properties of a material on the forming limit diagram for sheet metal in tension. International Journal of Mechanical Sciences. 1973;15:789-805.

[10] Marciniak Z. Sheet Metal Forming Limits. In: Koistinen D.P., Wang NM, editors. Mechanics of Sheet Metal Forming. Springer, Boston, MA, 1978, 215-235.

[11] Koistinen DP, Wang NM. Mechanics of sheet metal forming: material behavior and deformation analysis. Plenum Press New York, Springer US, 1978.

[12] Banabic D. A review on recent developments of M-K model. Computer Methods in Materials Science. 2010; 10(4):225-237.

[13] Banabic D. Sheet metal forming, Springer, 2010. 
[14] Nakazima K, Kikuma T, Hasuka K. Study on the formability of steel sheets. Yamata Technical Report: 264:8517-8530; 1968.

[15] Marciniak Z, Duncan JL, Hu SJ. Mechanics of sheet metal forming. Butterworth Heinemann, Oxford, 2002.

[16] Toroghinejad M, Dini G. Effect of Ti-micro alloy addition on the formability and mechanical properties of a low carbon (ST14) steel. International Journal of Iron \& Steel Society of Iran. 2006; 3:1-6.

[17] Lemaitre J, Chaboche JL. Mechanics of Solid Materials. Cambridge University Press, 1990.

[18] Evangelista SH, Lirani J, A Al-Qureshi H. Implementing a modified MarciniakKuczynki model using the FEM for the simulation of sheet metal deep drawing. Journal of Materials Processing Technology. 2002; 130-131:135-144.

[19] Robert Laminage SA Robert 2 St14 Pressing Steel DC04 DIN1.0338 technical datasheet. Retrieved from http://www.robertlaminage.ch ; 11 June 2018.

[20] Altmeyer G. Modélisation théorique et numérique des critères d'instabilité plastique. Application à la prédiction des phénomènes de striction et de localisation lors d'opérations de mise en forme par emboutissage. Dissertation, Arts et Métiers ParisTech, 2011.

[21] Ghosh AK. Strain localization in the diffuse neck in sheet metal. Metallurgical and Mater Transactions B. 1974; 5(7):1607-1616.

[22] Altmeyer G, Abed-Meraim F, Balan T. Investigation of some localization criteria and their relevance to prediction of forming limit diagrams. Steel Research International. 2010; 81(9):1364-1367.

[23] Butuc MC, da Rocha AB, Gracio JJ, Duarte JF. A more general model for forming limit diagrams prediction. Journal of Materials Processing Technology. 2002; 125 126:213-218.

[24] Cao J, Yao H, Karafillis A. Prediction of localized thinning in sheet metal using a general anisotropic yield criterion. International Journal of Plasticity. 2000; 16:11051129.

[25] Xu L, Chen L, De Cooman B, Steglich D, Barlat F. Hole expansion of advanced high strength steel sheet sample. International Journal of Material Forming. 2010; 3:247250.

[26] ASTM E2218-02 Standard Test Method for Determining Forming Limit Curves. ASTM International, West Conshohocken, PA; 2008.

[27] International organization for standardization ISO 12004-2:2008 Metallic materials Sheet and strip - Determination of forming-limit curves - Part 2: Determination of forming-limit curves in the laboratory; 2008.

[28] Hotz W, Timm J. Experimental determination of forming limit curves (FLC). P. Hora (Ed.), Procedings of the 7th Numisheet Conference and Workshop, Interlaken, Switzerland, 271-278; 2008.

[29] Banabic D, Lazarescu L, Paraianu L, Ciobanu I, Nicodim I, Comsa DS. Development of a new procedure for the expermimental determination of the forming limit Curves. CIRP Annals Manufacturing Technology. 2013; 255-258.

[30] Chu X. Caractérisation expérimentale et prédiction de la formabilité d'un alliage d'aluminium en fonction de la température et de la vitesse de déformation. Dissertation, INSA de Rennes, 2013. 
[31] Song X, Leotoing L, Guines D, Ragneau E. Investigation of the forming limit strains at fracture of AA5086 sheets using an in-plane biaxial tensile test. Engineering Fracture Mechanics. 2016; 163:130-140.

[32] Song X, Leotoing L, Guines D, Ragneau E. Characterization of forming limits at fracture with an optimized cruciform specimen:Application to DP600 steel sheets. International Journal of Mechanical Sciences. 2017; 126:35-43.

[33] Zwick Roell technical datasheet. Retrieved from https://www.zwickroell.com.

[34] Alejandro D, Escarpita A, Cardenas D, Elizalde H, Ramirez R, Probst O. Biaxial Tensile Strength Characterization of Textile Composite Materials. INTECH, 2012; 83-106.

[35] Tasan CC, Hoefnagels JPM, Dekkers ECA, Geers MGD. Multi-axial deformation setup for microscopic testing of sheet metal to fracture. Experimental Mechanics. 2012; 52: 669-678.

[36] Vempati SR, Brahama Raju K, Venkata Subbaiah K. Simulation of Ti-6Al-4V cruciform welded joints subjected to fatigue load using XFEM. Journal of Mechanical Engineering and Sciences. 2019; 13: 5371-5389.

[37] Haris A, Tay TE, Tan VBC. Experimental analysis of composite bolted joints using digital image correlation. Journal of Mechanical Engineering and Sciences. 2017; 11: 2443-2455.

[38] Samantaray BB, Mohanta CK. Analysis of industrial flame characteristics and constancy study using image processing technique. Journal of Mechanical Engineering and Sciences. 2015; 9: 1604-1613.

[39] Brunet M, Mguil-Touchal S, Morestin F. Numerical and experimental analysis of necking in $3 \mathrm{~d}$ sheet forming processes using damage variable. International Applied Mechanics. 1997; 45:205-214.

[40] Wang K, Carsley JE, He B, Li J, Zhang L. Measuring limit strains with digital image correlation analysis. Journal of Materials Processing Technology. 2014; 5:11201130.

[41] Martinez-Donaire AJ, Garcia-Lomas FJ, Vallellano C. New approaches to detect the onset of localised necking in sheets under through-thickness strain gradients. Materials \& Design. 2014; 57:135-145.

[42] Centeno G, Martinez-Donaire AJ, Morales-Palma D, Vallellano C, Silva MB, Martins PAF. Novel experimental techniques for the determination of the forming limits at necking and fracture, Materials forming and machining. Ed. Davim JP., Woodhead publishing in mechanical engineering, 2015. 